\title{
Study on Innovation in College English Teaching from the Perspective of Translation Aesthetics
}

\author{
Qiong Liu \\ College of Foreign Languages, Wuhan Donghu University , Wuchang Wuhan, 430212, China
}

\begin{abstract}
Keywords: Translation aesthetics, College English teaching, Text translation, Translation workshop, Teaching design
\end{abstract}

Abstract. English language, which has its unique beauty in tone, shape and implication and also has abundant connotations, is worthy of studying and deliberation, so college English teaching should not only be limited to the imparting and training of English listening, speaking, reading, writing and other basic skills and links but also start from the brand-new angle of translation aesthetics so as to bring more experiential teaching and innovative teaching for students to feel the beauty of language. This paper briefly analyzes the text translation characteristics and beauty-pursuing tactics of college English in the field of translation aesthetics and puts forward the specific curriculum design flow of college English teaching mode based on the translation workshop.

\section{Introduction}

Due to the difference between Chinese and western cultures, great attention should be paid to language translation. In the process of English translation, Chinese pursues the relative ambiguity of spirit and beauty. It is the so-called "no beauty in great beauty". Chinese pursues a sense of detachment, namely that "silence means more than words". This consonance and ingenious translation realm can meet the aesthetic standards for Chinese translation aesthetics. In text translation practices of college English teaching, the theory of translation aesthetics has an important guidance meaning, and focuses on good international communications as well as cultural exchange and conversions. How to choose the most appropriate vocabulary and grammar of target language to weaken the understanding difference caused by Chinese and western cultural aesthetics is also an ideal state pursued in college English teaching.

\section{Aesthetic expression of translation and aesthetic value of college English translation}

\section{View of aesthetic expression of translation aesthetics}

The basic duty of translation is to truthfully convert the source language with the target language as far as possible so as to "express the ideas of two languages." Besides, another more important duty of translation is to "express the feeling". We cannot unilaterally advocate alienation or naturalization in language translation but should take the enrichment of outstanding alienation of mother tongue as the target to promote reasonable communications. The cultural factor of language should also be taken into consideration.

Generally speaking, excellent translations can realize the most effective cross-cultural conversion form based on the cultural layer and thus achieve the complete harmony between Chinese and western cultures. Take A Dream in Red Mansions, a piece of ancient Chinese literary works, as an example. There are numerous English translation versions of A Dream in Red Mansions and the versions of by Gladys Margaret Tayler and Yang Hsien-yi are best accepted by western readers. When translating this great literary works, both of them adopted the translation method of "compensatory free translation", which can well realize the free cross-linguistic semantic exchange and integrate the cultural orientation of Chinese with the cultural orientation of translation by using perfect cultural and technical forms so that foreign readers can truly feel the love and hate contained in this works.

As for college English, the theory of translation aesthetics plays a more practical role of cultural aesthetics and is of strong guiding significance in teaching. Since college English pays attention to 
teaching students the interpersonal communications and the sense of beauty in translation, conversions on the cultural layer is especially emphasized in the process of translation teaching. It is required to choose the most proper vocabulary and grammar of target language to realize the weakening of aesthetic difference and to finally achieve the high-quality and effective communication mode. In teaching, the aesthetic expression of English syntagm is more demanding than Chinese because the thinking and concept of a sentence must be clear at any time. Each syntagm must have a meaning, make sense and be logical. In addition, the translation arrangement of syntagm should be orderly in unity and coherence. An excellent English syntagm translation must have a lead, supporting sentence, connecting sentence and concluding sentence. In English-Chinese translation, the source language can be translated to Chinese according to the original sequence. However, in Chinese-English translation, there is no lead in the Chinese syntagm and the internal structure is not precise due to the implicit quality of Chinese. For this reason, when learning translation, students should translate syntagms in accordance with the theory of Chinese aesthetics and had better add general sentences in the beginning of a syntagm to substitute the role of lead in English translation. Meanwhile, it is also required to properly adjust the internal structure of sentences and consider the correctness of grammar based on aesthetics so that the overall syntagm translated can attain the effect of proper organization and arrangement. Especially, it is required to consider the sense of balance of individual sentences because "focalization of subject and predicate" is stressed in English. It means that the subject and predicate in a sentence translated should not be too far away from each other; the ending form with prepositions should be avoided to the greatest extent and the translation of a long sentence needs to be controlled within 50 to 60 words.

\section{Aesthetic value of college English translation teaching}

\section{Beauty of loyalty}

The most important aesthetic value of English translation is the beauty of loyalty, which means the honesty and authenticity; namely, the translation needs to be highly consistent with the source text. For instance, with respect to business English contracts, documents and other basic non-artistic styles of translation, the first goal is to the preciseness, logicality and specialty of text translation. At this time, the English text translation needs to strictly comply with the principle and meaning of the source language to achieve faithful translation. Frivolous or exaggerated translation contents added in the translation process deviate from the preciseness in the theory of aesthetic translation and will even cause economic losses and credit losses among enterprises in public communication activities.

Beauty of simplicity

Business English translation stresses straightness and truth, thus the characteristic of simplicity must be highlighted. Especially, in the environment of fierce market competition and fast social development, English translation must be simple, concise and persuasive. For instance, the form of noun abbreviation or compound word is adopted in many business English translations, and many intentions can be expressed with just a short abbreviation to achieve the purpose of business communication. Therefore, during the college translation teaching, the original works must be fully respected based on the writing intention of the original title, and the translation must be proper, normative and concise, to achieve the final purpose of fully conveying the meaning of the original text to the opposite site and also the purpose of business activities.

\section{Beauty of agreement}

From the perspective of translation aesthetics, the agreement aesthetics has an important value attribute. It means thinking over translation in accordance with the stipulated principle and eliminating the arbitrariness in all translations, because there are abundant fixed phrases and collocations in the process of business English translation. Failure to match words according to such fixed methods in English translation teaching will result in to failure to meet the basic theoretical requirements of translation aesthetics and will even cause unnecessary business disputes between two parties.

To sum up, it is required to pay attention to details and principles in college English translation teaching. Using suitable translation grammars and skills in an occasion is particularly important. To help students to further understand the English application from the perspective of translation 
aesthetics, teachers must create new teaching modes and integrate the beauty-pursuing tactics with the teaching modes with innovative concepts to achieve the goal of improving teaching quality ${ }^{[1]}$.

\section{Design and application of college English teaching of translation workshop in colleges based on the beauty-pursuing tactics of translation aesthetics}

\section{Translation workshop}

The translation workshop, which sprung up in American colleges in 1960s, pays more attention to the effectiveness of teaching development based on the theory of translation aesthetics and is completely student-centered course-process-oriented free teaching mode. The translation workshop provides students with an almost commercial translation center instead of a classroom. In the process of translation teaching, students can communicate with each other and achieve the learning goal of "learning from doing", so it is a regular practice-cognition-practice process. In the teaching mode of translation workshop, students learn in groups, simulate the practical translation situations organized by teachers and complete specific translation tasks assigned by teachers through mutual discussion and coordination. In general, the translation workshop considers the creative thinking and skill improvement emphasized by it is exactly the aesthetics of translation. This paper designs the curriculum of college English translation teaching based on the mode of translation workshop and integrates the beauty-pursuing tactics into it in the hope of making an innovative breakthrough in English teaching ${ }^{[2]}$.

\section{Curriculum design of translation teaching based on the translation workshop Preparation before class}

It usually takes 20 to 30 minutes for preparation before class, which is mainly about that teachers explain translation knowledge and relevant problems, key points and difficulties involved in translation texts. For instance, when explaining the theory of translation, teachers basically need to focus on the application of translation principles and translation skills and stress that being clear and concise and catching the point are enough in the process of translation.

Before class, teachers should divide students into groups in advance, let students to gather translation materials in the form of group cooperation, and give them relevant English texts for preparation before class. At first, let students to try translation so that their problems in text translation can be highlighted and completely corrected in class.

\section{Class teaching}

After preparation before class and pre-writing of translated text, teachers need to deeply explain the preset English text in class and teach theoretical translation knowledge to students. This paper hopes to integrate the beauty-pursuing tactics into the process of English translation teaching based on the theory of translation aesthetics. Some teaching innovation strategies will be introduced as follows.

English correspondence translation strategies based on "quasi-ancient Chinese style" As for business letters, correspondences and other such information text subjects in college English, the teaching strategy should be different from ordinary letters, because more correct and concise translation languages are required in business letters; besides, the grammatical mood is relatively euphemistic; the format is more fixed; more attention is paid to the sense of beauty in translation. To correctly translate English letters into Chinese, it is more suitable to use a "quasi-ancient Chinese style”, which is a semi-ancient Chinese style between ancient Chinese style and vernacular style. Articles translated with such style has a more broad register, is more solemn and serious in the expression of source language, has a greater language bearing capacity and more concise effect, and can properly complete the communicative function of business letters. For instance:

\section{Dear Sir,}

In reply to your letter of May.10, we are pleased to inform you that we are willing to enter into business relations with you.

Your prompt reply will be greatly apprecitated.

Sincerely 
Translation：敬启方：兹复贵方5月10日来函，欣告我方愿与贵方建立商务关系。即复为 谢。谨上。

This section of Chinese translation is the semi-ancient Chinese style. With respect to an English information letter text, the “敬启方”, “贵方”, “欣告” and other semi-ancient Chinese style used in Chinese translation not only meet the cultural appeal of eastern tradition and the aesthetic standards but also conform to the aesthetic characteristics of mild and indirect mood in the other side' $\mathrm{s}$ English business letter.

Strategies for business English advertisement translation based on "conveying feelings and ideas"

Different from letters and telegrams, business English advertisements are of vocative texts, and their functions are to not only provide information, but also attract consumers' attention. It is quite common to encounter such text translation during college business English, thus different teaching strategies should be adopted to deal with it. From the theoretical perspective, it is far from enough to just achieve semantic equivalence during the business English advertisement translation; what should be achieved is the "conveying feelings and ideas", so as to achieve the aesthetic feeling of advertising language, stimulate consumers' purchasing behaviors and arouse the emotional resonance of audiences of the target language. In order to meet the needs of rendering the advertisement with rich emotional colors and aesthetic appreciation, here is an example for explanation:

Lash fantasy mascara-nourishing premier lifts and lengthens.Mascara darkens and thickens.longer,fuller,flirtier lashes.Let your fantasies run wild.

Translation: 幻睫毛亳: 滋养加长睫毛, 让你的睫毛更加乌黑浓密, 性感俏丽, 感受梦幻 般的美丽动人。

This advertisement uses coordinated comparative adjectives "longer”, “fuller” and "flirtier”, of which the purpose is to attract female consumers and arouse their desire of consumption. The aesthetic language in Chinese is not fully accordant with the English expression with comparative adjectives, because its intention is to use the aesthetic expression of Chinese language to approach the aesthetic effect that the original text wants to express. It can be hereby seen that there is a big difference between the aesthetic expression concepts of the same sentence in English and Chinese. The Chinese translation above makes the simple English comparative adjectives more vivid, which is also an aesthetic characteristic of Chinese translation.

\section{After-class evaluation}

According to the two translation strategies mentioned above, as far as the teaching method is concerned, teachers should transfer the power of initiative to students, allowing them to experience the role of translation aesthetics in business text translation. Therefore, teachers may put forward two kinds of teaching methods to implement the practice and after-class evaluation after theoretical course teaching.

Firstly, carry out the group discussion. The group learning is the concept of teamwork stressed in translation workshop. After the teacher finishes the teaching of translation theories, students start their translation tasks in groups and properly utilize the translation strategies. In order to improve the completion quality of group cooperative learning tasks and enhance the sense of reality of translation practice, teachers may lead students out of the classroom to the library, multimedia room and cinema for practical experience and translation teaching in more forms, and it is even possible to bring them to foreign enterprises for practical training and direct contact with business English environment, so as to feel the experience of English learning brought from different aesthetic cultures.

After-class evaluation is also an important part of English translation teaching; when students finish their translation tasks, teachers can organize students for mutual evaluation; the members of each translation group will exchange their works with the members of other groups for mutual evaluation, and the results of works evaluation will be shown to everybody; the teacher will summarize the problems and give an overall comment, after which students will carry out the works revision, gradually experience and seek for the charm of most graceful and elegant translation aesthetics during the works revision and keep improving ${ }^{[3]}$. 


\section{Conclusion}

Language translation itself is a kind of art, which requires certain skills and aesthetic ideas as the bases. The college English teaching based on the theory of translation aesthetics should be multi-dimensional, open and multi-layered. Of course, different translation strategies should be adopted for translating different business English contexts. Therefore, the English teaching methods and strategies must be flexible and innovative, and the cognition of repeated practice and the quintessential concept of cooperation stressed in translation workshop should be absorbed actively, so as to ensure high-quality and healthy development of college English teaching.

\section{References}

[1] Wang Fei. Business English Translation from the Aesthetic Perspective. Journal of Ningbo University of Technology, 2013, 25 (4): 5-10.

[2] Liu Yudan. Study on Business English Text Translation from the Perspective of Translation Aesthetics. Agricultural University Of Hunan, 2012, 34-41.

[3] Wang Yan. Application of Translation Workshop in Professional College English Translation. Inner Mongolia Normal University, 2013. 18-26. 